\title{
Educação Precoce: Interações Triádicas e Sistemas Semióticos
}

\author{
Early Education: Triadic Interactions and Semiotic Systems \\ Educación Temprana: Interacciones Triádicas y Sistemas Semióticos
}

\section{Lênia Márcia Gonçalves}

Professora mestra do Centro Universitário ICESP, Brasília, DF, Brasil

E-mail: leniamg@hotmail.com ORCID: https://orcid.org/0000-0002-6262-4359

Gabriela Sousa de Melo Mietto

Professora pós-doutora da Universidade de Brasília, Brasília, DF, Brasil

E-mail: gabriela.mieto@gmail.com ORCID: https://orcid.org/0000-0002-9868-4353

Recebido em 03 de março de 2021

Aprovado em 24 de outubro de 2021

Publicado em 18 de novembro de 2021

\section{RESUMO}

Este estudo se propõe a analisar as interações triádicas estabelecidas na Educação Precoce, de maneira a compreender os processos semióticos do bebê pré-verbal e o papel educativo de professores nesse contexto. O referencial teórico adotado é a perspectiva pragmática do objeto, que coloca que, para a compreensão do desenvolvimento do pensamento do bebê que ainda não fala, é necessário se trazer à luz a materialidade e o uso cultural de objetos nas interações bebê-adulto-objeto. Nesse sentido, foi realizada uma pesquisa empírica qualitativa com um bebê do sexo feminino, com histórico de prematuridade de 12 meses de idade cronológica, atendido na Educação Precoce, e sua professora. Os dados foram levantados com a ajuda de videogravação de uma sessão de atendimento da professora a esse bebê, com o uso de três objetos específicos. Estes dados foram analisados microgeneticamente, de modo que puderam ser observados os mediadores semióticos e os usos dos objetos empregados pela professora e pelo bebê no compartilhamento dos significados culturais subjacentes a estes sistemas. Os resultados indicam que a Educação Precoce tem um papel importante na construção dos primeiros sistemas semióticos de bebês pré-verbais, e, portanto, no processo de construção do seu pensamento, visto que é um espaço de interações triádicas intencionais, planejadas e consistentes. As práticas educativas contribuem significativamente para 0 ingresso de bebês na cultura e no mundo de significados, onde o professor atua como parceiro e guia. Palavras-chave: Educação precoce; Educação especial; Interações triádicas.

\section{ABSTRACT}

This study aims to analyze the triadic interactions established in Early Education, in order to understand the semiotic processes of the pre-verbal baby and the educational role of teachers in this context. The theoretical framework adopted is the pragmatic perspective of the object. Such framework states that, in order to understand the development of thought 
processes of the baby that still does not speak, it is necessary to bring light to the materiality and cultural use of the objects in the baby-adult-object interactions. In this sense, empirical qualitative research was carried out with a chronological 12-month-old female baby who attended in a school environment, and her teacher. The data was collected with the help of video recording of an educational session conducted by the teacher with this baby, using three specific objects. These data were analyzed micro genetically, so that the semiotic mediators and the uses of the objects used by the teacher and the baby in sharing the cultural meanings underlying these systems, could be observed. The results indicate that Early Education has an important role in the construction of the first semiotic systems of preverbal babies and, therefore, in the process of thought process, since it is an intentional, planned, and consistent triadic interactions space. The educational practices contribute significantly to the entry of this baby in culture and in the world of meanings, where the teacher plays the role of a partner and a guide.

Keywords: Early education; Special education; Triadic interactions.

\section{RESUMEN}

Este estudio tiene como objetivo analizar las interacciones triádicas que se establecen en la Educación Temprana, con el fin de comprender los procesos semióticos del bebé preverbal y el rol educativo de los docentes en este contexto. La teoría adoptada es la perspectiva pragmática del objeto, que establece que para comprender el desarrollo del pensamiento del bebé que aún no habla es necesario iluminar la materialidad y el uso cultural de los objetos en suyas interacciones con el adulto-objetos. Así, se realizó una investigación empírica cualitativa con una bebé de 12 meses de edad, asistida en un ambiente escolar y su maestra. Los datos fueron recolectados con la ayuda de la grabación de video de una sesión de asistencia de la maestra al bebé, utilizando tres objetos específicos. Estos datos fueron analizados micro genéticamente, de modo que pudieran observarse los mediadores semióticos y los usos de los objetos utilizados por la maestra y el bebé para compartir los significados culturales subyacentes a estos sistemas. Los resultados indican que por ser un espacio de interacciones triádicas intencionales, planificadas y consistentes, la Educación Temprana tiene un papel importante en la construcción de los primeros sistemas semióticos de los bebés preverbales y, por lo tanto, en el proceso de construcción de su pensamiento. En la educación temprana las prácticas educativas de los docentes contribuyen significativamente a la entrada del bebé en la cultura y en el mundo de los significados, desempeñando los maestros en este contexto, un papel de compañero y guía.

Palabras clave: Educación inicial; Educación especial; Interacciones triádicas.

\section{Introdução}

A atenção e o cuidado com a criança de risco, ou com deficiência, requer ações preventivas e interventivas desde o nascimento, uma vez que os primeiros anos de vida são considerados uma janela de oportunidade para o desenvolvimento do cérebro 
http://dx.doi.org/10.5902/1984686X64551

(UNICEF, 2021; BRASIL, 2014; 2016a). Ou seja, o momento ideal para práticas no lar ou em instituições voltadas à aprendizagem de bebês.

Embora essas crianças apresentem fatores que podem interferir negativamente em seu desenvolvimento, é consenso entre os pesquisadores da área que esses podem ser minimizados com sua participação em programas de intervenção precoce (CARNIEL et al., 2017). As descobertas da neurociência sobre como o cérebro se desenvolve e as mudanças que nele ocorrem resultantes das experiências e da neuroplasticidade corroboram com essa perspectiva, indicando que a intervenção precoce com crianças com deficiências ou de risco, são necessárias e trazem benefícios concretos para elas, suas famílias e a sociedade (NUNES; CHAHINI, 2017).

As iniciativas de intervenção educacional precoce no Brasil, tiveram início em 1995 a partir da publicação das “Diretrizes Nacionais sobre a Estimulação Precoce” pelo Ministério da Educação (MEC), cuja finalidade foi instituir e organizar o atendimento a crianças com deficiência entre 0 e 3 anos de idade. Esse documento traçou as primeiras diretrizes da Estimulação Precoce, oferecendo orientações para a identificação e o atendimento destas crianças em contexto escolar, com vistas a "minimizar, recuperar ou compensar as deficiências e seus efeitos" (BRASIL, 1995, p. 12; CARDOSO, FERNANDES; PROCÓPIO, 2017).

Estas práticas educativas se estruturaram ao longo do tempo e passaram a ser denominadas no Distrito Federal (DF) de "Educação Precoce", afastando-se da perspectiva médico-clínica que marcou seu início e avançando para um viés exclusivamente educativo de atendimento. O perfil das crianças atendidas no DF foi ampliado e inclui, hoje, os bebês de risco, isso é, aqueles que nasceram prematuramente (abaixo de 37 semanas); pesando abaixo de $2500 \mathrm{~g}$ ao nascimento, com apgar no $5^{\circ}$ minuto menor que 7 ; bebês cujas mães contraíram Zika vírus durante a gravidez, dentre outros (DE MIRANDA; DE SÁ, 2021; MINISTÉRIO DA SAÚDE, 2004; 2016). O perfil desse atendimento passou a incluir também bebês surdocegos, com atraso no desenvolvimento e com indicativo de altas habilidades/superdotação, além dos que apresentam deficiências (DISTRITO FEDERAL, 2010).

Baseado nessas considerações e nas contribuições da Educação Precoce para o desenvolvimento global das crianças de risco, este estudo se propõe a analisar as interações triádicas estabelecidas na Educação Precoce, de maneira a compreender os processos semióticos comunicativos do bebê pré-verbal e o papel educativo de professores 
http://dx.doi.org/10.5902/1984686X64551

neste contexto à luz da perspectiva teórica da pragmática do objeto (BÉGUIN, 2016; PALACIOS et al., 2015; RODRIGUEZ; MORO, 1999).

\section{Programas de intervenção precoce: Educação Precoce}

Os programas de intervenção precoce tiveram origem no programa americano Head Start, iniciado em 1965, e mais tarde no Early Head Start Program, criado na década de 1990. As ações eram direcionadas ao apoio às famílias em vulnerabilidade econômica e social, e às suas necessidades biopsicossociais (PEREIRA-SILVA; DESSEN, 2005; LOURENÇO, 2018).

O sucesso dos programas americanos levou outros países a desenvolverem trabalhos semelhantes, como os programas de Estimulación Temprana na Argentina na década de 1960, a Estimulacíon Precoz nos anos 70 na Espanha e, mais tarde, a Atención Temprana no mesmo país (HORN; LOPES, 2015; PÉREZ, 2009) e o serviço de Intervenção Precoce na Infância (IPI), em Portugal (BORGES; FLORES; SILVA, 2016; MIGUEL; PEREIRA, 2021; GRONITA et al. 2011), além do programa brasileiro. Essas iniciativas avançaram suas reflexões e hoje concordam que, para que sejam efetivas, as propostas devem incluir ações voltadas para o entorno das crianças, ampliando seu foco de intervenção também para a família e escola (PERPIÑÁN, 2019; HADDERS-ALGRA, 2017).

Acerca da efetividade dessas ações, um estudo realizado por Nores e Barnett (2010) analisou as evidências dos benefícios de programas de intervenção precoce em 23 países, concluindo que as crianças que participaram dessas iniciativas foram significativamente beneficiadas em vários aspectos, como a saúde, o comportamento, os aspectos escolares e cognitivos, além do desenvolvimento psicomotor, da linguagem e da socaliização (CABRERA; VÁSQUEZ; GOMES, 2020). Os avanços nessas questões foram mantidos ao longo do tempo, especialmente nos casos em que as intervenções foram de ordem educativa, nas quais os ganhos cognitivos foram mais expressivos. Soejima e Bolsanello (2012), Spittle et al. (2018) e Ferreira et al. (2020) se coadunam com esses achados, ao afirmarem que crianças de risco que participaram de programa de intervenção precoce evidenciaram uma progressão significativa no desenvolvimento global, confirmando a efetividade desse trabalho.

$\mathrm{Na}$ perspectiva educativa, a Educação Precoce tem caráter preventivo e busca atender as necessidades de cada criança por meio de estratégias pedagógicas personalizadas e adaptadas às demandas individuais. Esse programa se configura como 
http://dx.doi.org/10.5902/1984686X64551

Atendimento Educacional Especializado (AEE), e visa oferecer condições para que a criança desenvolva seu potencial nos aspectos físico, cognitivo, psicoafetivo, social e cultural, contribuindo para seu desenvolvimento global e inclusão social e educacional (DISTRITO FEDERAL, 2010, 2018).

A base do atendimento é a mediação do professor no processo de aquisição de competências humanas e sociais pelas crianças. Essa mediação está presente nas interações que são estabelecidas no contexto da escola com as crianças e suas famílias, ocorrendo de forma intencional e lúdica. Os objetivos de tais interações são pedagógicos e estão alinhados com as potencialidades e dificuldades das crianças e, sobretudo, relacionados ao meio sociocultural e o tempo histórico em que o bebê, sua família e o professor ou professora vivem.

As atividades desenvolvidas são planejadas a partir da compreensão de que a criança está em processo contínuo de construção e que aprende e se desenvolve na relação com o outro (VIGOTSKI, 2012). Os objetos pedagógicos e lúdicos são ferramentas de trabalho do professor que os introduz no contato com o bebê, estabelecendo, assim, interações triádicas (RODRÍGUEZ; MORO, 2008; MORO, 2016) que permearão todos os atendimentos da Educação Precoce (RODRÍGUEZ; MORO, 2008). Nessa perspectiva, o ato educativo é "revolucionário", pois implica na interação dos professores com o bebê e o mundo cultural representado pela materialidade, sendo capaz de provocar as mudanças e saltos qualitativos no curso do desenvolvimento infantil (DISTRITO FEDERAL, 2018, p.20). Por meio dessas interações, a criança transitará nos mundos social e cultural mesmo antes de falar de forma articulada, utilizando sistemas comunicativos cada vez mais complexos. O professor será seu guia nesse processo, oferecendo experiências semióticas fundamentais para o desenvolvimento do seu pensamento (ALENCAR; RENGIFOHERRERA, 2020; DUPERTUIS; MORO. 2016; RODRIGUEZ; MORO, 2008; VALE, 2019)

\section{O papel das interações sociais e da materialidade na primeiríssima infância}

A importância das interações sociais e da cultura na construção da subjetividade do sujeito foi proposta por Vigotski no início do século $X X$, e permanece atual: 0 desenvolvimento humano é resultante da interação do sujeito com o meio sócio-histórico e cultural, onde este afeta a cultura e ao mesmo tempo é afetado por ela, em um processo de transformações recíprocas e bidirecionais (TEIXEIRA; LÔBO; DUARTE, 2016). O 
http://dx.doi.org/10.5902/1984686X64551

ingresso no mundo cultural, que é repleto de significados, possibilita que o "indivíduo se torne sujeito" ao compartilhar com os outros as mesmas referências (GOMES et al, 2016, p. 817; MACHADO; LORETE, 2019).

O desenvolvimento é compreendido como um processo evolutivo, de natureza sociocultural, no qual as funções psicológicas superiores se desenvolvem a partir das relações entre os sujeitos, baseado na internalização dos sistemas de signos que são produzidos na cultura (VIGOTSKI, 1991). Para Brunner (1997), a cultura também constitui o sujeito, pois é por meio dela que as pessoas são capazes de dar significado aos atos intencionais uns dos outros. Com base nesses autores, pode-se afirmar que o ser humano é resultante das interaçoes sociais que acontecem nos diversos contextos nos quais ele vive, e dos significados que são criados e compartilhados entre eles, a partir de suas experiências com o outro (FERREIRA; MOURA; MIETO, 2020). O desenvolvimento, nessa perspectiva, é um processo sociogenético, marcado por saltos qualitativos, não lineares, onde a atividade mental resulta da interiorização da cultura e das relações sociais, esclarece Gomes (2014).

As interações sociais despertam grande interesse para a psicologia do desenvolvimento, em particular ao se considerar as crianças pequenas, afirmam Moura e Amorim (2018). Pesquisadores da primeira infância, fundamentados na teoria sóciohistórica, afirmam que o adulto introduz o bebê em um mundo repleto de significados desde o seu nascimento, atuando como organizador e intérprete desse universo semiótico (CAVALCANTE; RODRÍGUEZ, 2015; DIMITROVA, 2020; MOURA; AMORIM, 2018; RODRÍGUEZ et al., 2015). A partir dessa afirmação, conclui-se que as crianças que são atendidas em programas de Educação Precoce têm a oportunidade de ampliar as experiências com o adulto nas interações que são estabelecidas com seus professores, onde estes desempenham o papel de mediadores do seu desenvolvimento. Para realizar essa função, os professores e professoras se apoiam na ludicidade e no uso de brinquedos e objetos que representam a cultura do meio no qual estão inseridos, de maneira que esta interação se constitui como um dos pilares para o desenvolvimento infantil (MOURA; AMORIM, 2018). O papel educativo do professor se diferencia do papel parental, uma vez que no espaço da escola as atividades são planejadas para atingirem finalidades pedagógicas definidas e de modo intencional (MORENO-LLANOS; ZAPARDIEL; RODRÍGUEZ, 2020). 
http://dx.doi.org/10.5902/1984686X64551

Estudos mais recentes acerca desse tema, afirmam que a materialidade também faz parte dos processos de significação que a criança desenvolve ao longo do tempo e das interações das quais participa (RODRíGUEZ, 2009; BÉGUIN, 2016; MORENO-NUÑEZ; RODRÍGUEZ; DEL OMO, 2017). Desde o nascimento, o bebê está em contato com os objetos do cotidiano que são oferecidos pelo adulto ao interagir com ele. O bebê aprende a usar esses objetos por meio da mediação do adulto. Usar objetos envolve a atribuição de significados a partir de regras culturais de uso, representadas pela forma como são usados em uma comunidade. Essas regras são compartilhadas social e historicamente (ALESSANDRONI; RODRÍGUEZ, 2020). Nesse sentido, os objetos fazem parte das interações que ocorrem nos programas de Educação Precoce, não somente como um coadjuvante ou auxiliar no trabalho pedagógico, mas como um dos protagonistas dos primeiros processos semióticos envolvidos na construção do pensamento de bebês préverbais, perspectiva defendida pela pragmática do objeto.

\section{Pragmática do objeto}

Os primeiros três anos de vida da criança são muito ricos, repletos de mudanças desenvolvimentais sucessivas, que ocorrem em ritmo acelerado (FUERTES; LUÍS, 2014). As aprendizagens são numerosas e evidentes, e se dão de forma quantitativa e qualitativa, onde as interações com o outro e com o mundo físico são cruciais.

As interações bebê-adulto-objeto são a unidade básica a partir da qual é possivel compreender o desenvolvimento dos processos semióticos que ocorrem no contexto sóciohistórico e cultural no qual eles vivem (BÉGUIN, 2016; RODRIGUEZ; MORO, 1998), incluindo os atendimentos da Educação Precoce. Essas interações têm sido estudadas por diversos autores que compartilham sua importância para o desenvolvimento cognitivo da criança pré-verbal, seja em ambiente familiar ou escolar (ALENCAR; RENGIFOHERRERA, 2020; MORENO-NUÑEZ; FERNÁNDEZ-ALCAÍDE; MARTÍN-RUIZ, 2021). RENGIFO-HERRERA; RODRIGUES, 2020; RODRIGUEZ, 2009a; 2009b; RODRIGUEZ; MORO, 1999; MORO; RODRIGUEZ, 1991; VALE, 2019; NASCIMENTO, 2019). A pragmática do objeto se dedica a compreender os primeiros sistemas semióticos que a criança usa na construção do seu pensamento, um dos campos de trabalho fundamentais dos Educação Precoce.

A perspectiva pragmática do objeto propõe que os bebês não nascem sabendo usar, ou como funcionam, os objetos que os cercam. Isso deve ser aprendido socialmente, e o 
http://dx.doi.org/10.5902/1984686X64551

adulto tem papel fundamental ao lhe introduzir esse conhecimento e mediar esse processo de apropriação cultural, visto que é exatamente o seu uso que proporciona o conhecimento do seu significado (RODRÍGUEZ et al., 2018). Em outras palavras, para se conhecer o objeto e seu significado em uma cultura, é necessário conhecer seu uso e as regras que os governam, o que ocorre somente na interação triádica na infância, onde o objeto é um dos protagonistas. Quando o bebê nasce, o adulto busca se comunicar com ele e introduzi-lo no mundo semiótico usando objetos para atrair sua atenção, (MORENO-NUÑEZ et al. 2021; MORENO-NUÑEZ; RODRÍGUEZ; DEL OMO, 2015). Essas primeiras interações triádicas ocorrem a partir da intencionalidade comunicativa do adulto desde os primeiros meses de vida (ALESSANDRONI et al., 2019) e não somente após os 9 meses de idade, como defende Tomasello (2019). O bebê responde à essas ações desde muito cedo, voltando sua atenção para o adulto, que o convida a interagir com o mundo material por meio de mediadores semióticos, como os usos dos objetos, gestos, vocalizações e demonstrações (MORENO-NÚÑEZ; RODRÍGUEZ; DEL OLMO, 2015; 2017; RODRÍGUEZ, 2012). Aos poucos, o bebê passa a interagir com o adulto e os objetos de maneira intencional e ressignificada, utilizando também mediadores comunicativos baseados em suas experiências nas interações triádicas, perpassados pelos seus sentidos (BASILIO; RODRÍGUEZ, 2011; RODRIGUEZ; MORO, 1998).

Ao compartilhar o objeto com o bebê, o adulto indica como este deve ser usado canonicamente a partir das regras já estabelecidas socialmente. O adulto assume, dessa maneira, um papel educativo ativo, direcionando o bebê nos processos semióticos cada vez mais complexos que se desdobram com base nos diferentes usos dos objetos (GUEVARA; MORENO-LHANOS; RODRÍGUEZ, 2020; MORENO-LLANOS; ZAPARDIEL; RODRÍGUEZ, 2020).

Para conhecer o uso do objeto, a criança passa por inúmeras etapas não lineares de desenvolvimento dos processos semióticos. Inicialmente, o objeto e seu uso não significam a mesma coisa (RODRÍGUEZ; MORO, 1999; HERRERA, 2005). Há um hiato entre o objeto físico, que ainda é desconhecido e não tem um nome, mas que pode ser visto, tocado e usado. O uso convencional em uma cultura depende de um aprendizado que ele ainda não teve. Neste momento, o objeto físico não significa nada além do que pode ser visto pelo bebê mas, por outro lado, seus usos implicam regras culturais e significados atribuídos pelo outro (MORENO-NUÑEZ; FERNÁNDEZ-ALCAIDE; MARTÍN-RUIZ, 2021). O objeto, nesse sentido, é polissêmico, uma vez que estão fundidas suas características materiais e físicas 
http://dx.doi.org/10.5902/1984686X64551

com suas caracterísiticas socioculturais que estão presentes em seus usos (MORO \& RODRÍGUEZ, 2002; PALACIOS, 2009). O primeiro sistema semiótico comunicativo usado pelo adulto e pelo bebê, são os usos rítmicos-sonoros dos objetos. Esses usos implicam em movimentar objetos diante do bebê de forma rítmica e a fim de produzir sons, quer esses objetos apresentem esse componente ou não. Estas são formas comunicativas iniciais, que buscam atrair a atenção do bebê e compartilhar com ele um objeto que pode ser usado desta forma que, em alguns casos, coincidem com seu uso canônico (MORENONUÑES; ALESSANDRONI, 2021; MORENO-NUÑEZ; FERNÁNDEZ-ALCAIDE; MARTÍNRUIZ, 2021; MORENO-NUÑEZ; RODRÍGUEZ; DEL OMO, 2015; 2017).

Concomitante aos usos rítmicos e sonoros, o adulto usa os objetos de forma convencional ou canônica, isto é, baseado nas regras de uso que foram compartilhadas publicamente em uma comunicade. $\mathrm{O}$ adulto atua como mediador das informações culturais do contexto em que vivem, guiando o bebê nos processos semióticos que ocorrem por meio desta forma de uso (RODRÍGUEZ; LOS REYES, 2021).

Além do uso canônico, o adulto usa frequentemente os objetos de forma simbólica nas interações triádicas. Esse tipo de uso se refere a situações nas quais um objeto é usado no lugar de outro que está ausente. Assim, um copo pode ser usado como um chapeu ao ser colocado na cabeça, ou uma argola como uma pulseira, ao ser introduzida no braço. Essa forma de uso ocorre desde muito cedo nas interações triádicas, sendo realizada pelo adulto diante do bebê, ainda que esse compreenda seu significado e não consiga usar o objeto tal qual o adulto (RODRIGUEZ, 2009a). Ao final do primeiro ano, o bebê já será capaz de usar o objeto simbolicamente baseando esta ação nas regras dos usos canônicos deles. (PALACIOS, RODRÍGUEZ; MENDEZ-SANCHEZ, 2018; RODRÍGUEZ; LOS REYES, 2021).

O desenvolvimento dos processos semióticos do bebê perpassa pelos diferentes tipos de uso dos objetos nas interações triádicas, com níveis de complexidade progressivos, embora não sejam lineares. Inicialmente, o bebê usa o objeto com base em suas características físicas e nas possibilidades de uso que ele apresenta, ou affordances ${ }^{1}$ (DIMITROVA, 2020; GIBSON, 1979), sem se basear nos signos que o adulto está compartilhando. Esse tipo de uso é desconectado de seu uso convencional compartilhado social e culturalmente, se constituindo como uso não canônico. Ao usar o objeto dessa maneira, de acordo com Rengifo-Herrera e Rodrigues (2020), o bebê apenas manuseia os objetos sem uma intenção definida. A partir da intervenção do adulto, que repete os usos 
http://dx.doi.org/10.5902/1984686X64551

culturais de um objeto diante da criança, esses passarão a ter um significado cultural e a fazer parte de sua vida. Esse processo se refere à construção do pensamento da criança, uma vez que pensar implica dar significado ao que a rodeia, incluindo ao mundo material. Dar significado a algo só ocorre pela mediação semiótica do outro (RODRíGUEZ; MORO, 1998).

Antes de usar canonicamente o objeto, o bebê realiza ações mais dirigidas e com intencionalidade que se aproximam deste tipo de uso, embora anda não o faça com autonomia. O uso protocanônico indica que o bebê já sabe como usar o objeto convencionalmente e está realizando tentativas e esboços nesta direção (RODRíGUEZ et. al, 2017). Nesse caso, o bebê ainda não desenvolveu completamente sua coordenação motora para ser bem-sucedido nessa ação.

A construção do uso canônico do objeto requer tempo e trabalho, onde a mediação do adulto é fundamental (RODRÍGUEZ; MORO, 2008). O adulto servirá como modelo de como usar os objetos, partindo do uso rítmico-sonoro e do não canônico, até os usos simbólicos, em níveis crescentes de complexidade dos processos semióticos e, portanto, de pensamento (MORENO-NUÑEZ; RODRÍGUEZ; DEL OMO, 2015; 2017; PALACIOS; RODRÍGUEZ, 2015; RODRÍGUEZ; MORO, 1998). Esse processo é não linear, dinâmico e marcado pelas estabilidades, avanços e retrocessos que caracterizam o desenvolvimento humano. Isso significa que o bebê irá transitar entre os diferentes tipos de usos dos objetos, se apoiando também em mediadores semióticos não verbais para se comunicar com o outro e pensar. $O$ adulto usa também esses mediadores não verbais, uma vez que esses facilitam a compreensão dos significados compartilhados por ele com o bebê. Esses mediadores semióticos são os gestos ostensivos de mostrar, dar, sacudir o objeto diante do bebê, os gestos indexicais de apontar o objeto que está ditante do bebê, as vocalizações e as demonstrações de como usar os objetos (BASILIO; RODRÍGUEZ, 2011; 2017; RODRÍGUEZ, 2009).

Como o adulto, o bebê também usa mediadores semióticos não verbais para se comunicar acerca do objeto e por meio deles, sobretudo quando ainda não dispõe da linguagem articulada (GUEVARA; MORENO-LHANOS; RODRÍGUEZ, 2020). Os gestos ostensivos são produzidos por ambos, se configurando como uma modalidade efetiva de comunicação a partir do direcionamento da atenção a um referente que está presente, física ou simbolicamente (MORENO-NUÑEZ, RODRIGUEZ; MIRANDA-ZAPATA, 2020). No início, o bebê não compreende o significado dos gestos relizados pelo adulto, entretanto, 
mais tarde, percebe que eles estão relacionados aos objetos e a seus usos, passando a empregá-los também na sua comunicação não-verbal (RODRÍGUEZ; PALACIOS, 2007).

Os gestos ostensivos são aqueles em que o bebê usa o objeto para se comunicar acerca dele, de forma que o signo e o referente coincidem (BASILIO; RODRÍGUEZ, 2017). Podem ser protodeclarativos e protoimperativos, e foram o foco de estudos iniciais acerca das comunicação pré-verbal (BATES; VOLTERRA; CAMAIONI, 1975; WETTLING, 2016). Essas formas iniciais comunicativas são voltadas para o outro e buscam a interação a partir da materialidade ou de eventos que ocorrem no contexto. Os gestos protodeclarativos ocorrem quando o bebê direciona o objeto para o adulto, a fim de compartilhar seu interesse e o próprio objeto com ele. Os gestos protoimperativos são usados quando o bebê direciona o objeto para o adulto com o objetivo de obter sua ajuda para que alcance algum objetivo (DURAND et al., 2020). A pragmática do objeto introduz outro tipo de gesto ostensivo, que são os gestos protointerrogativos, observados nas ações do bebê de direcionar o objeto para o adulto para que ele regule sua ação diante do desafio de usar o objeto canonicamente (RODRÍGUEZ, 2009b).

Ao serem direcionados para si mesmo, os gestos são chamados de privados e são uma forma de comunicação consigo mesmo e de pensamento do bebê, que passa a ser externa (DURAND et al., 2020; RODRÍGUEZ; PALACIOS, 2007; RODRÍGUEZ, 2009b; BASILIO; RODRÍGUEZ, 2011). Os gestos podem ser exploratórios ou ter uma função reflexiva e autorregulatória, quando o bebê olha o objeto e o estuda, buscando maneiras de resolver o problema do seu uso convencional, regulando internamente suas ações para alcançar esse objetivo.

Para compreender os significados dos gestos, é necessário, entretanto, estar atento ao contexto em que ele ocorre, à situação e ao próprio objeto (RODRíGUEZ, 2007; 2009b). Os gestos usados pela criança pré-verbal se relacionam com o mundo material e às circunstâncias interativas concretas nas quais ocorrem, onde seus significados se alinham ao contexto comunicativo, aos objetos ao qual se referem e aos usos que se faz deles. Isso significa que os gestos são produzidos de acordo com um cenário comunicativo específico que se apresenta a partir do uso dos objetos, indicando que o signo representado por ele está pragmaticamente direcionado.

Com base nos aportes teóricos aqui apresentados, torna-se fundamental trazer ao campo de reflexões as interações triádicas que ocorrem em programas de Educação Precoce, uma vez que suas práticas educativas envolvem também bebês pré-verbais, nos 
quais a linguagem articulada ainda não está estabelecida como ferramenta de pensamento. Compreender as interações que ocorrem entre o bebê, seu professor e os objetos que os cercam, bem como papel deste profissional na apropriação dos sistemas semióticos pelo bebê, são cruciais para a realização de um trabalho educativo intencional e planejado, voltado para a construção do pensamento dessas crianças.

\section{Método}

\section{Contexto e participantes}

Trata-se de uma pesquisa empírica qualitativa, realizada em uma escola pública de Educação Infantil do Distrito Federal, que oferece a Educação Precoce. Todos os procedimentos realizados no curso dessa pesquisa, foram aprovados pelo Comitê de Ética em Pesquisa em Ciências Humanas e Sociais (CEP-CHS) da Universidade de Brasília, com registro CAAE 10095319.0.0000.5540.

Os participantes desse estudo foram selecionados a partir da análise documental dos bebês atendidos na Educação Precoce. Participaram dessa pesquisa um bebê prematuro (31 semanas) do sexo feminino, com 12 meses de idade cronológica, e sua professora. Optou-se pelo trabalho com crianças prematuras, visto que estudos em língua portuguesa baseados na pragmática do objeto e com esse perfil de crianças são raros. A idade cronológica de 12 meses foi definida com base em estudos anteriores com a mesma base teórica realizados com bebês nascidos a termo, que apontam o final do primeiro ano como o momento em que as crianças já são capazes de utilizar sistemas comunicativos préverbais mais complexos. O sexo foi indiferente. No início da coleta dos dados, o bebê era atendido em duas sessões semanais de 45 minutos com a professora pedagoga, sendo também participante dessa pesquisa.

Os atendimentos foram realizados em sala própria para atendimento a bebês, composta por armário com brinquedos, pia com trocador, espelho, barra de apoio e tatame, entre outros. Durante o atendimento, o bebê e professora se posicionaram sentados no tatame, de frente um para o outro.

\section{Material}

Foram selecionados três objetos lúdicos que tinham a característica de permitir usos canônicos. Foram utilizados: 1) porco-espinho com 10 orifícios em sua parte superior para encaixe de 10 de hastes coloridas. Seu uso convencional é colocar as hastes nos orifícios; 
http://dx.doi.org/10.5902/1984686X64551

2) caixa de ovos com 6 espaços de encaixe para ovinhos, que, quando retirada a casca, revelam um pintinho colorido e, ao serem pressionados, produziam um som de piado. Seu uso convencional é tirar e colocar o ovo na caixa, abrir e fechar o ovo, pressionar pintinho para produzir som; 3) torre composta por argolas de diferentes tamanhos, espessuras, cores e texturas para encaixe na haste que está fixa em uma base. Uma das argolas é transparente e possui esferas coloridas soltas dentro, de modo que quando movimentada, produz barulho de chocalho. Seu uso canônico é encaixar as argolas na torre ou sacudir a argola transparente para produzir som.

\section{Procedimentos de construção e análise dos dados}

Após autorização da Secretaria de Estado de Educação do DF, foi feito contato com a direção da escola e com o coordenador da Educação Precoce para apresentação do projeto de pesquisa e permissão local para seu início.

Na primeira etapa, foram solicitados os documentos escolares e médicos dos bebês de até 12 meses de idade em atendimento para análise inicial. Selecionado um bebê que atendia aos critérios pré-estabelecidos, foi feito o contato com a professora desse bebê e, em seguida, com sua mãe, a fim de convidá-los a participarem desse estudo e colher de ambas a assinatura do Termo de Consentimento Livre e Esclarecido (TCLE) e demais documentos exigidos pelo CEP-CHS para pesquisa com seres humanos.

A interação da professora com o bebê e com os objetos usados durante o atendimento de Educação Precoce foram videogravadas durante cerca de 16 minutos. Foi orientado que a professora realizasse $\mathrm{o}$ atendimento da maneira rotineira usando, entretanto, três objetos específicos. Cada objeto foi usado individualmente nas interações triádicas, durante tempo varável, de acordo com o interesse e engajamento do bebê. O porquinho foi usado por $3 \mathrm{~min} 43 \mathrm{~s}$, o pintinho por $6 \mathrm{~min} 37 \mathrm{~s}$ e a torre por $5 \mathrm{~min} 3 \mathrm{~s}$. Para cada objeto, foi realizada uma vídeogravação, totalizando três episódios. Optou-se pela videogravação pelo fato desse recurso permitir que o pesquisador retorne inúmeras vezes ao contexto e às interações captadas, o que possibilita a análise minuciosa dos micros eventos que ocorreram (GÓES, 2000; ESCOBEDO, 2020).

As vídeogravações foram realizadas pela pesquisadora na sala de atendimento para os bebês da escola. A mãe permaneceu na sala de atendimento, embora não tenha participado diretamente das atividades. Os brinquedos foram oferecidos montados, em ordem aleatória. 
A partir dos dados obtidos, foi realizada sua análise microgenética, de maneira que os detalhes e microcomportamentos apresentados pelo bebê e pela professora nas interações triádicas foram observados e estudados. Esse tipo de análise está atento às minúcias das interações sociais, permitindo o olhar e um acompanhamento sobre processos que ocorrem em um espaço de tempo, com o foco nas ações dos sujeitos e em como interagem (GÓES, 2000; BARBOSA; VAZ, 2019), se constituindo como ferramenta ideal para essa pesquisa.

A primeira etapa foi a descrição dos vídeos e o levantamento de categorias e subcategorias iniciais de análise. Estas categorias e subcategorias foram inspiradas em estudos com a mesma base teórica realizados em contexto domiciliar (RODRIGUEZ; MORO, 1999; PALACIOS, 2015; GERBASSI, 2021). Em seguida, as videogravações foram inseridas no software ELAN (EUDICO Linguistic Annotator, versão 5.9), ferramenta de análise de áudio e vídeo desenvolvido pelo Max Plank Institute, que foi alimentado, também, com outras que emergiram no decorrer da análise dos dados.

De cada episódio, foi selecionado um trecho de interações triádicas com tempo variável, considerando seu início e conclusão. Desta maneira, o trecho do objeto porquinho foi de $2 \mathrm{~min} 24 \mathrm{~s}$ de duração, do pintinho $1 \mathrm{~min} 43 \mathrm{~s}$ e da torre e $1 \mathrm{~min} 39 \mathrm{~s}$. Estes trechos foram analisados microgeneticamente, segundo a segundo, diversas vezes, o que permitiu a identificação dos micros comportamentos presentes nos diversos tipos de usos dos objetos e dos mediadores semióticos comunicativos utilizados pelo bebê e a professora nas interações com cada objeto.

As categorias usadas para o bebê se referem aos diversos usos dos objetos, a saber: usos rítmicos-sonoros, não canônicos, protocanônicos e simbólicos. Quanto à categoria de gestos do bebê foram estudados: os gestos ostensivos privados, privados indexicais, protoimperativos, protodecalarativos, protointerrogativos e simbólicos. Para a professora, as categorias criadas corresponderam às do bebê, no que se refere aos usos dos objetos. Os gestos da professora categorizados foram os ostensivos e indexicais. Outros mediadores semióticos usados pela professora fizeram parte das categorias principais, como as demonstrações e verbalizações. Nessa última foram incluídas as subcategorias de mostrar o objeto, perguntar algo acerca dele, atribuir-lhe características físicas e de instruir sobre os usos dos objetos. 
http://dx.doi.org/10.5902/1984686X64551

\section{Resultados e discussão}

A partir dos dados obtidos nas videogravações, foram analisadas as interações triádicas na Educação Precoce e os sistemas semióticos comunicativos verbais e não verbais relacionados aos usos dos objetos.

As interações triádicas ocorreram a partir da intencionalidade comunicativa da professora, que as iniciou com o objeto porquinho, quando o ofereceu ao bebê por meio de gestos ostensivos (dar, mostrar, movimentar), a fim de chamar sua atenção e envolvê-lo na atividade proposta. Esses gestos ostensivos foram frequentemente acompanhados de verbalizações ao mostrar o objeto, chamando o bebê a olhá-lo, fazer perguntas acerca do objeto, atribuir características físicas aos objetos (cor, forma, peso, tamanho e textura) e ainda instruir o bebê sobre o que fazer com o objeto.

Os mediadores semióticos verbais e não verbais foram usados pela professora durante as interações triádicas de forma a estimular o engajamento do bebê na proposta do uso de cada objeto de diferentes formas, seu interesse nessa atividade e as aprendizagens relacionadas ao seu trabalho pedagógico, como no caso dos conceitos acerca das características físicas. Dessa maneira, os objetos foram apresentados ao bebê por partes, e as ações da professora foram relacionadas inicialmente a elas. Cada parte do objeto e das ações da professora possuíam significados diferentes do uso canônico do objeto completo. A segmentação do mundo em aspectos que chamam a atenção do bebê visa compartilhar significados mais fáceis de serem compreendidos. Esses significados se referem ao uso canônico de partes do objeto (RODRIGUEZ; MORO, 2008) e tem lugar no compartilhamento a atenção, e dos significados menos complexos. Assim, a professora, antes de usar o objeto de forma convencional mais elaborada, como colocar as argolas na torre, pegou uma delas, a girou, movimentou e bateu uma contra a outra, dividindo com o bebê este referente, para depois usar canonicamente o objeto completo incluindo estas partes. Essa ação permite ao bebê que volte sua atenção para parte do objeto, seu uso e para a professora, facilitando sua compreensão do uso canônico que será apresentado posteriormente.

Ao apresentar o pintinho, a professora usou os mesmos mediadores semióticos usados com o porquinho, associando os gestos ostensivos à música que fazia referência a um pintinho amarelinho. Esta música, muito usada durante as aulas de musicalização das quais o bebê também fazia parte, remete às características físicas do objeto pintinho, pois uma delas era ser de cor amarela e de produzir um som de piado. Geralmente, ao cantar essa música diante do bebê, a professora estava com o pintinho dessa cor em sua mão, ou 
http://dx.doi.org/10.5902/1984686X64551

próximo dela. $\mathrm{O}$ bebê reagiu à música sorrindo e produzindo os gestos que a acompanhavam, tais como colocar o dedo indicador na palma da mão, o que indica que ele compreendeu o seu significado nesse contexto cultural específico. A questão da produção dos gestos e seu significado contextualizado com a circunstância na qual ele ocorre, foi abordada por Rodríguez (2009b), que considera que a forma ou a função da comunicação gestual estão conectadas ao ambiente cultural e material nas quais ocorrem. Nesse caso, o objeto pintinho se relaciona com os gestos que foram realizados tanto pela professora quanto pelo bebê, e com a música cantada por ela naquele contexto específico.

A professora usou igualmente gestos de mostrar, acompanhados de verbalizações, para que o bebê voltasse sua atenção para as argolas e a torre montada, ou parcialmente montada. Esses gestos e verbalizações de mostrar foram repetidos ao longo das suas diferentes formas de uso. Outros mediadores semióticos verbais como perguntar e instruir o bebê acerca dos objetos e seus usos, também foram observados nas ações da professora com frequência significativa. Pode-se inferir que essas verbalizações foram usadas a fim de estimular o bebê a realizar essas ações relacionadas aos usos dos objetos e, concomitantemente, sua agencialidade diante da possibilidade de escolha em realizar as tarefas apresentadas ou da manifestação do seu desejo, em uma perspectiva de construção da autonomia, conforme orientado no Currículo em Movimento do Distrito Federal (DISTRITO FEDERAL, 2018).

Os objetos foram usados de diferentes maneiras pela professora diante do bebê, especialmente de forma não canônica. Essa ação ocorreu com o porquinho, nas diversas vezes em que introduziu seu dedo nos orifícios no lugar das hastes, e com a torre, ao girar as argolas em seu próprio eixo. O uso não canônico do objeto diz respeito ao seu uso de forma indiferenciada, apartada do seu uso convencional e a partir de suas características físicas, ou seus affordances (RODRÍGUEZ; MORO, 1999; RODRÍGUEZ et al., 2007; RIBAS, 2021). Essa ação também foi observada particularmente no início das interações, visto que os objetos usados nesse estudo eram novos para o bebê, isto é, era a primeira vez que ele os via. Esses usos não canônicos da professora a partir de partes do objeto, como discutido acima, se relacionam com a segmentação do mundo em tarefas mais significativas para o bebê e mais fáceis de realizar e compreender, ainda que tenham pouca ou nenhuma relação com o uso convencional (RODRíGUEZ, 2012; GERBASSI, 2021).

A professora usou também os objetos de forma rítmica-sonora. Essa ação se refere as situações em que ela golpeou os objetos uns contra os outros, o que ocorreu entre as 
hastes do porquinho, entre as casquinhas e os ovinhos e as argolas contra a torre ou entre si. Essa ação da professora produzia sons, geralmente rítmicos, e tinha a finalidade de atrair a atenção do bebê para o objeto, reconduzindo-o para a interação triádica. Esses tipos de usos foram identificados em estudos anteriores que descreveram as ações do adulto ao usar objetos a partir de seu componente sonoro, quando ele já apresenta essa possibilidade, como no caso da torre que tem uma argola que produz som. Também foram observados os usos de objetos que não produziam sons, como uma de suas características, mas que foram usados para essa finalidade, como no caso das argolas comuns da torre, das hastes ou das casquinhas dos ovinhos (MORENO-NUÑEZ; RODRÍGUEZ; DEL OMO 2015; 2017; ALENCAR, 2020).

Os objetos foram usados também canonicamente pela professora, ocorrendo concomitantemente com os demais usos. Nesse sentido, a professora demonstrou como usar os objetos a partir das convenções sociais compartilhadas culturalmente e acordadas entre ela e o bebê (RODRIGUEZ; PALACIOS, 2007; BENASSI; RODRÍGUEZ, 2020). As hastes, portanto, deveriam ser colocadas nos orifícios do porquinho, as argolas encaixadas na torre e os ovinhos na caixinha (ou serem usados de outras formas canônicas, como pressionar o pintinho e produzir som, fechar o pintinho com a casquinha, fechar a caixinha). Embora o bebê ainda não fosse capaz de usar os objetos dessa maneira por imaturidade motora, a professora demonstrou como fazê-lo, se posicionando como modelo da ação (RODRIGUEZ; MORO, 1999). Ao demonstrar como usar o objeto canonicamente, a professora introduziu o bebê no mundo semiótico onde o objeto era signo do seu uso, dividindo com ele um significado já estabelecido social e culturalmente (RODRÍGUEZ; MORO, 1999; 2008; CÁRDENAS; MORENO’NUÑEZ; MIRANDA-ZAPATA, 2020).

O bebê participou ativamente das interações triádicas, pegando os objetos oferecidos pela professora e por iniciativa própria, se engajando em seus diferentes usos. A forma predominante do uso dos objetos pelo bebê foi a não canônica, isto é, a partir de suas possibilidades físicas, e não do seu uso cultural (YUSTE, 2017). Essas formas estiveram presentes no uso do porquinho, do pintinho e da torre, quando os componentes desses objetos foram levados frequentemente à sua boca. A situação do bebê levar o objeto à sua boca foi abordada por Rodriguez (2009a), ao afirmar que a zona oral do bebê, além de ter uma função de nutrição, vai se orientando, ao longo do tempo, para uma função de exploração do mundo, o que pôde ser observado, também, nesse estudo. 
http://dx.doi.org/10.5902/1984686X64551

Os usos rítmicos-sonoros realizados pelo bebê também estiveram presentes nas interações triádicas, embora de forma pouco frequente, especialmente com o porquinho. Esses usos são as primeiras formas comunicativas que são usadas tanto pelo bebê, quanto pelo adulto (DEL OMO; RODRÍGUEZ; TARRIO, 2010; MORENO-NUÑEZ; RODRIGUEZ; DEL OMO, 2015; MURILO; MONTEIRO; CASLA, 2019) e se referem a ação de movimentálo de forma cadenciada, podendo produzir ou não sons. Isso pôde ser observado nos momentos em que o bebê sacudiu as argolas no ar, ou as golpeou contra a torre, ou nas ocasiões em que bateu a haste do porquinho contra a outra. A professora realizou essas mesmas ações, acrescidas de bater a casquinha do pintinho no espelho ou uma contra a outra, a fim de produzir sons que chamassem a atenção do bebê e se comunicar com ele por meio do uso do objeto (MORENO-NUÑEZ; RODRIGUEZ; DEL OMO, 2015; 2017).

O bebê compreendeu o uso canônico do objeto a partir das demonstrações da professora, apoiadas nos demais mediadores semióticos não verbais e verbais, uma vez que foram observados usos protocanônicos neste estudo, ainda que em poucas ocasiões. Os usos protocanônicos são tentativas de uso canônico do objeto. Indicam que o bebê já sabia como usar o objeto canonicamente, porém, ainda não conseguia fazê-lo sem ajuda da professora. Essa forma de uso se aproxima dos usos canônicos e podem ser consideradas, também, formas de autorregulação do bebê diante da tarefa de usar o objeto canonicamente (RODRÍGUEZ et al., 2017). Assim, o bebê experimentou e analisou ativamente a melhor maneira de executar a ação de usar o objeto a partir dos usos realizados pela professora, perpassado pelos significados acordados entre eles. Os usos canônicos também estiveram presentes nas ações do bebê, embora de forma incipiente. Não foram observados usos simbólicos nas ações do bebê ou da professora.

Os gestos foram usados pelo bebê para se comunicar com a professora e consigo mesmo. Os gestos predominantes foram os ostensivos privados, que dizem respeito aos momentos em que o bebê pegou o objeto e o direcionou para si mesmo a fim de analisá-lo, estudá-lo e compreender seu significado, ora com objetivo exploratório, ora para autorregular a ação de usar o objeto (BASILIO; RODRíGUEZ, 2011; RODRÍGUEZ, 2009b). O bebê pegou os componentes do objeto como as hastes, o pintinho ou as argolas e, em diversas ocasiões, os olhou atentamente, movimentando-os em suas mãos, para em seguida abandoná-los ou usá-los de alguma das formas, em particular a canônica. Esses gestos desempenham um papel básico no surgimento das funções executivas, visto que o bebê traça um objetivo pessoal acerca do uso canônico do objeto, se comunica consigo mesmo por meio dos gestos, 
http://dx.doi.org/10.5902/1984686X64551

usando-o como uma estratégia de pensamento externo, buscando a melhor maneira de ter sucesso, e depois executa a ação (GUEVARA, et al., 2020).

Os gestos ostensivos direcionados ao outro também foram encontrados nas interações triádicas. Esses gestos são mediadores semióticos comunicativos usados pelo bebê que ainda não fala, a fim de se comunicar com o adulto (RODRíGUEZ, 2009b). Os gestos ostensivos que foram voltados para a professora tinham a função protodeclarativa, isso é, do bebê compartilhar com ela seu interesse sobre o referente e sobre o próprio objeto. Essa ação foi observada nos momentos repetidos em que o bebê mostrou a argola com o chocalho para a mãe ou para a professora, depois de tê-la pegado, analisado, sacudido e produzido som. Os gestos privados indexicais, protoimperativos, protointerrogativos e simbólicos privados não foram observados nesse estudo.

\section{Considerações finais}

A Educação Precoce é realizada, fundamentalmente, por meio de interações entre professores, crianças e os objetos que compõe este espaço. Estes objetos lúdicos são as ferramentas do trabalho pedagógico e fazem parte da rotina dos atendimentos, sendo apresentados e usados diariamente nas práticas educativas. Os professores e professoras usam constantemente mediadores semióticos a fim de que a criança compreenda e se aproprie dos signos culturais que cada objeto representa, sendo esses marcados por normas públicas de como devem ser usados.

Todos os objetos têm funções, regras de uso e significados que são compartilhados em um contexto histórico, social e cultural. Professores e professoras fazem parte do processo de apropriação desses sistemas de significados ao dividir essas regras com as crianças atendidas na Educação Precoce, de maneira que o objeto vai se tornando signo do seu uso ao longo do tempo e das interações triádicas.

Inicialmente, professora e bebê atribuem ao objeto significados diferentes, pois o bebê o reconhece a partir de suas características físicas e possibilidades de uso (affordances), desconectado de seu uso cultural, e a professora já conhece seu uso e significado cultural. A partir da ação da professora, o significado do objeto na cultura é compartilhado, gerando um acordo entre o que o bebê conhece sobre o objeto e o que a professora lhe mostrou, de modo que seu uso canônico, como representante de normas culturais, passa a fazer parte do universo semiótico do bebê. Essa operação pressupõe tempo, uma vez que os níveis de complexidade semiótica que requerem os diversos tipos de usos são diferentes. 
http://dx.doi.org/10.5902/1984686X64551

Esses usos vão dos mais básicos, como o uso não canônico, até os mais complexos, como os usos simbólicos, que são alcançados ao final do primeiro ano de idade. Para alcançar os usos simbólicos é necessário um trabalho educativo consistente e contínuo, como o da Educação Precoce, quando se trata de bebês com deficiência ou de risco.

Ao longo das interações triádicas, professoras ou professores e bebês que ainda não falam, usam mediadores semióticos não verbais para se comunicarem uns com os outros acerca dos objetos, por meio deles e seus usos. Os gestos são uma ferramenta fundamental que auxilia o bebê a compreender o objeto e seu uso, mesmo antes que ele seja capaz de usá-lo canonicamente. Esses gestos ostensivos convidam o bebê para o compartilhamento com o adulto de sua atenção e de um referente comum, e os guiam na apropriação dos sistemas semióticos relacionados a ele. Ao serem usados pelo bebê, têm os mesmos objetivos comunicativos que os adultos, e ainda outros adicionais, como a possibilidade de se autorregular e de pensar por meio dessa ação.

Operar sistemas semióticos cada vez mais complexos implica na construção do pensamento. A construção do pensamento perpassa pela apropriação de diversos sistemas semióticos que aumentam em complexidade, onde o bebê dá significado ao que o rodeia, iniciando esse processo por meio da materialidade. Assim, esse processo pressupõe interações triádicas desde os primeiros meses de vida, de maneira que esses sistemas se tornem ferramentas que o bebê usará para pensar antes que possa usar a linguagem articulada. A Educação Precoce oferece essas oportunidades por meio do trabalho educativo do professor, que utiliza recursos pedagógicos intencionais e planejados, ricos em diversidade. Nesse sentido, as interações triádicas que ocorrem em ambiente escolar diferem das interações triádicas realizadas no lar. A partir da triadicidade, o bebê ingressará no mundo dos significados culturais, utilizando os objetos de forma cada vez mais elaborada, avançando na construção dos signficados culturais da materialidade que 0 cerca, onde o professor/professora será seu parceiro e seu guia nesse processo.

Embora tenha trazidos resultados interessantes para a compreensão dos processos semióticos do bebê prematuro em ambiente escolar, esse estudo apresenta limitações. Julga-se necessário avançar nas pesquisas com um número maior de participantes de ambos os sexos, adotando um delineamento longitudinal de pesquisa, a fim de que seja possível acompanhar as transições entre os diversos tipos de usos dos objetos, dos gestos nas interações triádicas, inclusive após o surgimento da linguagem articulada. 
http://dx.doi.org/10.5902/1984686X64551

\section{Referências}

ALENCAR, Ana Carolina Correa; RENGIFO-HERRERA, Francisco José. La alimentación en la educación infantil a la luz de la perspectivca triádica del desarrollo. Investigación y Práctica en Psicología del Desarrollo, Aguascalientes, v. 5, p.117-151, jan. 2019.

ALENCAR, Ana Carolina Correa. Dinâmicas triádicas entre cuidadores-objetos-crianças em situações educacionais e lúdicas sobre alimentação em uma escola de educação infantil do DF. Dissertação (Mestrado Profissional em Educação). Universidade de Brasília, Brasília, 2021.

ALESSANDRONI, Nicolás; RODRÍGUEZ, Cintia. On perception as the basis for object concepts: A critical analysis. Pragmatics \& Cognition, Amsterdam, v. 26, n. 2-3, p. 321356, dez. 2019.

ALESSANDRONI, Nicolás et al. Musical dynamics in early triadic interactions: A case study. Psychological Research, v. 84, n. 6, p. 1555-1571, mar. 2020.

BARBOSA, João P. V.; VAZ, Arnaldo M. Análise microgenética de processos de aprendizagem na pesquisa em educação em ciências. Revista Electrónica de Enseñanza de las Ciencias, v. 18, n. 3, p. 458-477, 2019. Disponível em: http://revistas.educacioneditora.net/index.php/REEC/article/view/344. Acesso em 25 ago. 2021.

BASILIO, Marisol; RODRÍGUEZ, Cintia. Usos, gestos y vocalizaciones privadas: de la interacción social a la autorregulación. Infancia y Aprendizaje, v. 34, n. 2, p. 181-194, 2011.

BASILIO, Marisol; RODRÍGUEZ, Cintia. How toddlers think with their hands: Social and private gestures as evidence of cognitive self-regulation in guided play with objects. Early Child Development and Care, v. 187, n. 12, p. 1971-1986, 2017.

BATES, Elizabeth; CAMAIONI, Luigia; VOLTERRA, Virginia. The acquisition of performatives prior to speech. Merrill-Palmer quarterly of behavior and development, v. 21 , n. 3, p. 205-226, 1975.

BÉGUIN, Marie. Object pragmatics and language development. Integrative Psychological and Behavioral Ccience, v. 50, n. 4, p. 603-620, ago.2016.

BENASSI, Julia; RODRÍGUEZ, Cintia. The genesis of shared reference. A pragmatic perspective of autism (Génesis de la referencia compartida. Una mirada pragmática sobre el autismo). Journal for the Study of Education and Development, v. 43, n. 4, p. 779-792, 2020.

BORGES, Gabriela Silva Braga; FLORES, Maria Marta Lopes; SILVA, Janaina Cassiano. A estimulação precoce de crianças público-alvo da educação especial na educação infantil. In: Estudos interdisciplinares em humanidades e letras. Neves, Adriana Freitas et al. (org). São Paulo: Blucher, 2016. 558 p. Disponível em: https://repositorio.ivc.br/handle/123456789/389. Acesso em: 9 set. 2021. 
http://dx.doi.org/10.5902/1984686X64551

BRASIL. Ministério da Educação. Diretrizes educacionais sobre estimulação precoce. Brasília, DF,1995. p. 44. Disponível em:

http://www.dominiopublico.gov.br/download/texto/me002557.pdf. Acesso em: 6 jul. 2020.

BRASIL. Ministério da Saúde. Agenda de compromissos para a saúde integral da criança e redução da mortalidade infantil. Brasília, DF, 2004. p.80. Disponível em: http://bvsms.saude.gov.br/bvs/publicacoes/agenda_compro_crianca.pdf. Acesso em: 5 dez. 2020.

BRASIL. Ministério da Saúde. Manual atenção à saúde do recém-nascido (Guia para Profissionais de Saúde), v. 1, Brasília, DF, 2014. p.195. Disponível em: https://bvsms.saude.gov.br/bvs/publicacoes/atencao_saude_recem_nascido_v1.pdf. Acesso em: 3 jul. 2020.

BRASIL. Ministério da Saúde. A estimulação precoce na atenção básica: guia para abordagem do desenvolvimento neuropsicomotor pelas equipes de Atenção Básica, Saúde da Família e Núcleo de Apoio à Saúde da Família no contexto da síndrome congênita por zika. Brasilia, DF, 2016. Disponível em:

http://189.28.128.100/dab/docs/publicacoes/geral/estimulacao_precoce_ab.pdf. Acesso em: 6 dez. 2020.

BRUNNER, Jerome. Atos de significação. Porto Alegre: Artes Médicas, 2007.

CABRERA, Ibian Dahiana Montero; VÁZQUEZ, Yadnil Elizabeth Gómez; GÓMEZ, Onelis Góngora. Efectividad de la estimulación temprana en lactantes con riesgos de retardo en el desarrollo psicomotor. Correo Científico Médico, v. 24, n. 2, 2020. Disponível em: http://www.revcocmed.sld.cu/index.php/cocmed/article/view/3446 . Acesso em: 15 set. 2021.

CÁRDENAS, Karina; MORENO-NÚÑEZ, Ana; MIRANDA-ZAPATA, Edgardo. Shared Book-Reading in Early Childhood Education: Teachers' Mediation in Children's Communicative Development. Frontiers in Psychology, v. 11, 2020.

CARDOSO, Carolina; FERNANDES, Leandra Procópio; PROCÓPIO, Marcos. Estimulação precoce na educação infantil: um estudo bibliométrico. Revista EDaPECI, v. 17, n. 1, p. 166-187, 2017. Disponível em: https://dialnet.unirioja.es/servlet/articulo?codigo=6711128. Acesso em: 21 ago. 2021.

CARNIEL, Camila Zorzetto et al. Influência de fatores de risco sobre o desenvolvimento da linguagem e contribuições da estimulação precoce: revisão integrativa da literatura. Rev. CEFAC, São Paulo, v. 19, n. 1, p. 109-118, fev. 2017. Disponível em: https://www.scielo.br/j/rcefac/a/VGrstgWgMdcJyHr5stDfpyP/?format=pdf\&lang=pt. Acesso em: 23 dez. 2020.

CAVALCANTE, Silvia; RODRÍGUEZ, Cintia. The understanding of die as an object that has numerical functions. A longitudinal study using two children from the ages of 24 to 36 months interacting with an adult/La comprensión del dado como objeto con funciones numéricas. Un estudio longitudinal con dos niños desde los 24 a los 36 meses en interacción con un adulto. Estudios de Psicología, v. 36, n. 1, p. 48-70, fev. 2015. 
DE MIRANDA, Maria Auristela Barbosa Alves; DE SÁ, Antônio Villar Marques.

Atendimento Educacional Especializado para a primeiríssima infância: O Programa de Educação Precoce no Distrito Federal. Revista Com Censo: Estudos Educacionais do Distrito Federal, v. 7, n. 2, p. 173-180, 2020.

DEL OLMO, María Jesús; RODRÍGUEZ, Cintia; TARRÍO, Francisco Ruza. Music therapy in the PICU: 0-to 6-month-old babies. Music and Medicine, v. 2, n. 3, p. 158-166, 2010.

DIMITROVA, Nevena. The role of common ground on object use in shaping the function of infants' social gaze. Frontiers in psychology, v. 11, p. 619, 2020. Disponível em: https://www.frontiersin.org/articles/10.3389/fpsyg.2020.00619/full. Acesso em: 10 set. 2021

DISTRITO FEDERAL. Orientações pedagógicas da educação especial. Brasília, DF, 2010. 142 p. Disponível em

http://www.cre.se.df.gov.br/ascom/documentos/subeb/ed_especial/orient_pedag_ed_esp ecial2010.pdf. Acesso em: 25 nov. 2020.

DISTRITO FEDERAL. Currículo em movimento da educação básica: educação infantil. Brasília, DF, 2018. 106 p. Disponível em: http://www.educacao.df.gov.br/wpconteudo/uploads/2018/02/Curri\%CC\%81culo-em-Movimento-Ed-Infantil_19dez18.pdf. Acesso em: 24 nov. 2020.

DUPERTUIS, Virginie; MORO, Christiane. Self-directed ostensions and mediations of the adult at the age of 8-, 12-and 16 months. Integrative Psychological and

Behavioral Science, v. 50, n. 4, p. 621-633, 2016.

DURAND, María Florencia et al. El desarrollo de la comunicación preverbal y verbal temprana. La importancia del juego. Revista Iberoamericana de Psicología: Ciencia y Tecnología, v. 13, n. 1, p. 23-31, 2020

ELAN. (Versão 5.9.). EUDICO Linguistic Annotator [software de computador]. Nijmegen: Max Planck Institute for Psycholinguistics. Holanda, 2020. Disponível em: https://archive.mpi.nl/tla/elan. Acesso em 20 jun. 2020.

ESCOBEDO, Pedro Antonio Sánchez. Prescripciones metodologicas para el uso de viedograbacion en la investigacion educativa/methodological prescriptions for the use of video recording in educational research. MLS Educational Research, v. 4, n. 2, p. 1c1c, 2020.

FERREIRA, Juliene Madureira; MOURA, Gabriella Garcia; MIETO, Gabriela Sousa de Melo. Children's Sociability in Institutional Contexts: Theoretical Reflections on Cognitive Development Within Peer Interactions. Human Arenas, p. 1-21, 2020.

FERREIRA, Rachel de Carvalho et al. Effects of early interventions focused on the family in the development of children born preterm and/or at social risk: a meta-analysis. Jornal de Pediatria, v. 96, p. 20-38, 2020. Disponível em: https://www.scielo.br/j/jped/a/K3LL6W6kdtH8ghTZJJsQ5Bc/abstract/?lang=en. Acesso em: 16 set. 2021. 
FUERTES, Marina; LUÍS, Helena. Vinculação, práticas educativas na primeira infância e intervenção precoce. Interacções, v. 10, n. 30, jun. 2014. Disonível em:

https://revistas.rcaap.pt/interaccoes/article/view/4023. Acesso em: 23 dez 2020.

GERBASSI, Thaís Neves. Atenção compartilhada nas relações triádicas: um estudo a partir da mãe e seus filhos. Dissertação (Mestrado em psicologia do desenvolvimento e Escolar).Universidade de Brasília, Brasília, 2021.

GIBSON, James J. The ecological approach to visual perception. Houghton Mifflin. New York, 1979.p.174.

GÓES, Maria Cecília Rafael de. A abordagem microgenética na matriz histórico-cultural: uma perspectiva para o estudo da constituição da subjetividade. Cad. CEDES, Campinas, v. 20, n. 50, p. 9-25, abr. 2000. Disponível em: http://www.scielo.br/scielo.php?script=sci_arttext\&pid=S0101 32622000000100002\&Ing=en\&nrm=iso._Acesso em: 24 out. 2021.

GOMES, Cláudia Aparecida Valderramas. Afetos, cultura e mediação: especificidades do desenvolvimento na criança de zero a três anos. Perspectiva, v. 32, n. 3, p. 813-828, dez. 2014. Disponível em:

https://periodicos.ufsc.br/index.php/perspectiva/article/view/2175-795X.2014v32n3p813. Acesso em: 20 nov 2020.

GOMES, Isadora Dias et al. O social e o cultural na perspectiva histórico-cultural: tendências conceituais contemporâneas. Psicol. rev. (Belo Horizonte), Belo Horizonte, v. 22, n. 3, p. 814-831, dez. 2016. Disponível em: http://pepsic.bvsalud.org/scielo.php?script=sci_arttext\&pid=S1677$11682016000300016 \&$ lng=pt\&nrm=iso . Acesso em: 24 dez. 2021.

GRONITA, Joaquim et al. Intervenção precoce: o processo de construção de boas práticas: relatório final. Lisboa: Fundação Calouste Gulbenkian, 2011.212 p. Disponível em: https://repositorioaberto.uab.pt/handle/10400.2/7364. Acesso em: 18 nov. 2020.

GUEVARA, Irene; MORENO-LLANOS, Iván; RODRÍGUEZ, Cintia. The emergence of gestures in the first year of life in the Infant School classroom. European Journal of Psychology of Education, v. 35, n. 2, p. 265-287, jan. 2020.

HORN, Daiane; LOPES, Maria Isabel. A prática cotidiana dos educadores de bebês de 0 a 2 anos. Olhares \& Trilhas. n. 2, jul. 2015. Disponível em:

http://www.seer.ufu.br/index.php/olharesetrilhas/article/view/29400/16931. Acesso em: 10 nov. 2020.

HERRERA, Francisco José Rengifo. El símbolo es, del ojo, la pupila: Primeras aproximaciones al surgimiento de la Agencialidad en la relación Niño-ObjetoAdulto. Páginas: Revista académica e institucional de la UCPR, n. 73, p. 3, 2005. Disponível em: https://revistas.ucp.edu.co/index.php/paginas/article/view/2258. Acesso em 6 dez. 2020. 
RENGIFO-HERRERA, Francisco José; GOMES MELO RODRIGUES, Ana Paula. Quando comer não é suficiente: Tríade, cuidado/educação, desenvolvimento e uso dos objetos durante as refeições em duas creches do DF. Psicología desde el Caribe, v. 37, n. 3, set/dez. 2020.Disponível em:

http://rcientificas.uninorte.edu.co/index.php/psicologia/article/view/12334. Acesso em 5 jan. 2020.

LOURENÇO, Natália Sofia Quintas. Intervenção Precoce na Infância: atuação profissional dos Educadores de Infância sobre os riscos do desenvolvimento infantil. Tese Doutorado (Escola Superior de Educação de Paula Frassinetti). Portugal, Porto, 2018. Disponível em: http://repositorio.esepf.pt/handle/20.500.11796/2582. Acesso em 22 ago. 2021.

MACHADO, Suzana Grimaldi; LORETE, Eliane Oliveira (2019). Educação inclusiva: múltiplas práticas e olhares. Instituto Federal do Espírito Santo. Disponível em: https://vendanova.ifes.edu.br/images/stories/E-book___Educação_Inclusiva__múltiplas_práticas_e_olhares.pdf. Acesso em: 16 set. 2021.

MIGUEL, Marta Isabel Quelhas; PEREIRA, Cristina Maria Gonçalves. Intervenção Precoce: Estudo comparativo entre Portugal e Espanha. New Trends in Qualitative Research, [S. I.], v. 7, p. 115-127, 2021. DOI: 10.36367/ntqr.7.2021.115-127. Disponível em: https://publi.ludomedia.org/index.php/ntqr/article/view/312. Acesso em: 8 set. 2021

MORENO-LLANOS, Iván; ZAPARDIEL, Laura A.; RODRÍGUEZ, Cintia. Children's first manifestations of cognitive control in the early years school: the importance of the educational situation and materiality. European Journal of Psychology of Education, $p$. 1-20, 2020. Disponível em: https://link.springer.com/article/10.1007/s10212-020-00505-1. Acesso em: 17 ago. 2020.

MORENO-NÚÑEZ, Ana; ALESSANDRONI, Nicolás. What's an early triadic interaction made of? A methodological proposal to study the musical dynamics of interaction. Infant Behavior and Development, v. 63, p. 101572, 2021. Disponível em: https://www.sciencedirect.com/science/article/pii/S0163638321000473. Acesso em: 19 ago. 2021.

MORENO-NÚÑEZ, Ana; FERNÁNDEZ-ALCAIDE, Ainhoa; MARTÍN-RUIZ, Noemí. EI desarrollo de las interacciones triádicas tempranas. Revista de Psicología, p. 088-088, 2021.

MORENO-NúÑEZ, Ana; RODRÍGUEZ, Cintia; DEL OLMO, María Jesús. The rhythmic, sonorous and melodic components of adult-child-object interactions between 2 and 6 months old. Integrative Psychological and Behavioral Science, v. 49, n. 4, p. 737-756, fev. 2015.

MORENO-NúÑEZ, Ana; RODRÍGUEZ, Cintia; DEL OLMO, María Jesús. Rhythmic ostensive gestures: How adults facilitate infants' entrance into early triadic interactions. Infant Behavior and Development, v. 49, p. 168-181, nov. 2017.

MORENO-NÚÑEZ, Ana; RODRÍGUEZ, Cintia; MIRANDA-ZAPATA, Edgardo. Getting away from the point: the emergence of ostensive gestures and their functions. Journal of child language, v. 47, n. 3, p. 556-578, 2020. 
MORO, Christiane. To encounter, to build the world and to become a human being. Advocating for a material-cultural turn in developmental psychology. Integrative psychological and behavioral science, v. 50, n. 4, p. 586-602, 2016.

MORO, Christiane; RODRÍGUEZ, Cintia. ¿ Por qué el niño tiende el objeto hacia el adulto? La construcción social de la significación de los objetos. Infancia y Aprendizaje, v. 14, n. 53, p. 99-118, 1991.

MOURA, Gabriella Garcia; AMORIM, Kátia de Souza. Interações de bebês em acolhimento familiar e institucional: dois estudos exploratórios. Psicologia em Estudo, v. 23, out. 2018. Disponível em: https://periodicos.uem.br/ojs/index.php/PsicolEstud/article/view/40287. Acesso em: 5 nov. 2020.

NASCIMENTO, Priscila. Dias. O desenvolvimento cultural do bebê: o uso do livro como objeto mediador. Dissertação (Mestrado em Processos de Desenvolvimento Humano e Saúde). Universidade de Brasília, Brasília, 2019.Disponível em:

https://repositorio.unb.br/handle/10482/37278. Acesso 19 nov. 2019.

NORES, Milagros; BARNETT, W. Steven. Benefits of early childhood interventions across the world:(Under) Investing in the very young. Economics of education review. v. 29, n.2, p. 271-272, abr. 2010. Disponível em:

https://www.sciencedirect.com/science/article/abs/pii/S027277570900106X_. Acesso em: 22 nov.2020.

NUNES, Ana Silvia Duarte; CHAHINI, Thelma Helena Costa. Percepções de profissionais da educação infantil em relação à estimulação precoce em crianças com deficiência e de risco ambiental. Revista Interdisciplinar em Cultura e Sociedade. vol 3, n.1. p. 83-102. jan./jun. 2017. Disponível em:

http://www.periodicoseletronicos.ufma.br/index.php/ricultsociedade/article/view/7222.

Acesso em: 5 nov. 2020.

PALACIOS, Pedro. Origen de los usos simbólicos de los objetos en los niños contextos de comunicación e interacción triádicos. Tese (doutorado). Universidad Autónima de Madrid. Madrid, p.379. 2009. Disponível em:

https://repositorio.uam.es/bitstream/handle/10486/4029/27818_palacios_salas_pedro.pdf?s equence=1. Acesso em: 6 dez. 2020.

PALACIOS, Pedro et al. Usos y significados de los objetos en niños mexicanos. Investigación Y Práctica En Psicología Del Desarrollo. vo1, p 15-20, jan, 2015. Disponível em: https://revistas.uaa.mx/index.php/ippd/article/view/627. Acesso em: 2 jul. 2020.

PALACIOS, Pedro; RODRÍGUEZ, Cintia; MÉNDEZ-SÁNCHEZ, Cecilia. Communicative mediation by adults in the construction of symbolic uses by infants. Integrative

Psychological and Behavioral Science, v. 52, n. 2, p. 209-227, 2018.

PEREIRA-SILVA, Nara Liana; DESSEN, Maria Auxiliadora. Intervenção precoce e família: Contribuições do modelo bioecológico de Bronfenbrenner. In: Maria Auxiliadora Dessen; COSTA JUNIOR, Áderson Luiz. (Org.). A ciência do desenvolvimento humano:

Tendências atuais e perspectivas futuras. Porto Alegre: Artmed. 2005. p 151-167. 
PÉREZ, Vicente Quirós. Nuevo modelo para la atención temprana en Andalucía: directrices y desafíos. Revista Iberoamericana de Educación. v. 48, n. 4. febrero de 2009.

Disponível em: https://rieoei.org/historico/expe/2592Quirosv2.pdf. Acesso em: 10 nov. 2020.

PERPIÑÁN, Sonsoles. Atención temprana y familia: cómo intervenir creando entornos competentes. Narcea Ediciones, 2019.

RIBAS, Luana de Melo. O processo criador da criança com autismo em espaços brincantes: imaginação-emoção e o coletivo. Dissertação (Mestrado em Psicologia do Desenvolvimento e Escolar), Universidade de Brasília, Brasília, 2021.

RODRÍGUEZ, Cíntia. Object use, communication and sings. The triadic basis of early cognitive development. In: VALSINER, Jaan; ROSA, Alberto (Eds.), The Cambridge handbook of sociocultural psychology. New York: Cambridge University Press, 2007. p. 257-276.

RODRÍGUEZ, Cintia. El ojo de Dios no mira signos. Desarrollo temprano y semiótica. Infancia y Aprendizaje, v. 30, n. 3, p. 343-374, 2007.

RODRÍGUEZ, Cintia. O nascimento da inteligência: do ritmo ao símbolo. Porto Alegre: Artmed, 2009a.

RODRÍGUEZ, Cintia. The 'circumstances' of gestures: Proto-interrogatives and private gestures. New ideas in Psychology, v. 27, n. 2, p. 288-303, ago. 2009b.

RODRÍGUEZ, Cinta.? El adulto como guia ¿ el eslabón perdido del desarrollo temprano? Padres y maestros, 2012a. Disponível em:

https://repositorio.uam.es/bitstream/handle/10486/662884/adulto_rodriguez_PyM_2012.pd f?sequence=1. Acesso em: 20 ago. 2020.

RODRÍGUEZ, Cíntia ; LOS REYES José Luiz de. Los objetos sí importan Acción educativa en la escuela infantil. Horsori, 2021

RODRÍGUEZ, Cintia; MORO, Christiane. El uso convencional también hace permanentes a los objetos. Infancia y aprendizaje, v. 21, n. 84, p. 67-83, 1998.

RODRÍGUEZ, Cíntia; MORO, Christiane. El mágico número três: Cuando los niños aún no hablan. Barcelona: Paidós, 1999.

RODRÍGUEZ, Cintia; MORO, Christiane. Objeto, comunicación y símbolo. Una mirada a los primeros usos simbólicos de los objetos. Estudios de psicología, v. 23, n. 3, p. 323338, 2002.

RODRÍGUEZ, Cintia; MORO, Christiane. Coming to agreement: Object use by infants and adults. In: ZLATEV, Jordan et al. (Ed.). The shared mind: Perspectives on intersubjectivity. Benjamins Publishing. p. 89-114, 2008.

RODRÍGUEZ, Cintia; PALACIOS, Pedro. Do private gestures have a self-regulatory function? A case study. Infant behavior and development, v. 30, n. 2, p. 180-194, mai. 2007. 
http://dx.doi.org/10.5902/1984686X64551

RODRÍGUEZ, Cintia et al. Ostensive gestures come first: their role in the beginning of shared reference. Cognitive Development, v. 36, p. 142-149, out. /dez. 2015.

RODRÍGUEZ, Cintia et al. Executive Functions and educational actions in an infant school: private uses and gestures at the end of the first year/Funciones Ejecutivas y acción educativa en la Escuela Infantil: usos y gestos privados al final del primer año. Studies in Psychology, v. 38, n. 2, p. 385-423, 2017.

RODRÍGUEZ, Cintia et al. Object Pragmatics: Culture and Communication-the Bases for Early Cognitive Development. In ROSA, Alberto; Valsiner, Jaan. The Cambridge handbook of sociocultural psychology. Cambridge University Press. United Kingdom: p. 223- 244, 2018.

RODRÍGUEZ, Cintia et al. Executive Functions and educational actions in an infant school: private uses and gestures at the end of the first year/Funciones Ejecutivas y acción educativa en la Escuela Infantil: usos y gestos privados al final del primer año. Studies in Psychology, v. 38, n. 2, p. 385-423, mai. 2017.

SOEJIMA, Carolina Santos; BOLSANELLO, Maria Augusta. Programa de intervenção e atenção precoce com bebês na educação infantil. Educ. rev., Curitiba, n. 43, p. 65-79, mar. 2012. Disponível em: http://www.scielo.br/scielo.php?script=sci_arttext\&pid=S010440602012000100006\&lng=en\&nrm=iso. Acesso em 24: ago. 2020.

SPITTLE, Alicia J. et al. The role of social risk in an early preventative care programme for infants born very preterm: a randomized controlled trial. Developmental Medicine \& Child Neurology, v. 60, n. 1, p. 54-62, 2018. Disponível em: https://onlinelibrary.wiley.com/doi/full/10.1111/dmcn.13594. Acesso em: 7 set. 2021

TEIXEIRA, Alcylanna Nunes; LÔBO, Karla Rossana Gomes; DUARTE, Ana Teresa Camilo. A Criança e o ambiente social: aspectos intervenientes no processo de desenvolvimento na primeira infância. Id on Line Revista de Psicologia, v. 10, n. 31, p. 114-134, 2016.

TOMASELLO, Michael. Becoming human. Harvard University Press, 2019.

UNICEF. Desenvolvimento Infantil (acesso em 5 de dezembro de 2021). Disponível na internet via https://www.unicef.org/brazil/desenvolvimento-infantil.

VALE, Vilma Gonçalves do. Sistemas semióticos em contexto de aprendizagem: criança com Síndrome de Down-professora do AEE-jogo matemático. Dissertação (Mestrado em Processos de Desenvolvimento Humano e Saúde). Universidade de Brasília. Brasília, p.148, 2019. Disponível em:

https://repositorio.unb.br/handle/10482/37786. Acesso em: 15 set. 2019.

VIGOTSKI, Lev Semionovitch. A formação social da mente: o desenvolvimento dos processos psicológicos superiores. 4aㅡ ed. São Paulo: Martins Fontes, 1991.

VOLTERRA, Virginia. Merrill-Palmer Quarterly of Behavior and Development. Detroit, Wayne State University Press, 1975.p 205-226. Disponível em https://www.researchgate.net/publication/232508320_The_Acquisition_of_Performatives_ Prior_to_Speech. Acesso em: 2 dez. 2020. 
WETTLING, Ignacio. Intenciones comunicativas tempranas. Consideraciones para la Evaluación. Revista Digital EOS Perú, v. 7, n. 1, p. 42-55, 2016

YUSTE, Noemí Blázquez. Primeros usos simbólicos con objetos réplica y artefacto con niños/as de 9 a 24 meses. Tese (doutorado). Universidad autónima de Madrid. Madrid, 2017, p.161 Disponível em: https://repositorio.uam.es/handle/10486/680694. Acesso em 09 mai. 2020.

\section{Notas}

1 Possibilidades oferecidas pelo objeto (tradução nossa).

(c) (i) (8)

This work is licensed under a Creative Commons Attribution-NonCommercial 4.0 International (CC BY-NC 4.0) 